\section{Síndrome de burnout e fatores associados: um estudo epidemiológico com professores}

\author{
Factors associated with burnout's syndrome: \\ an epidemiological study of teachers
}

\author{
1 Universidade Luterana \\ do Brasil, Canoas, Brasil. \\ Correspondência \\ M. S. Carlotto \\ Universidade Luterana \\ do Brasil. \\ Av. Farroupilha 8001 \\ Canoas, RS \\ 22031-200, Brasil. \\ mscarlotto@superig.com.br
}

\begin{abstract}
This article presents the results of an epidemiological study on burnout syndrome among private school teachers in Greater Metropolitan Porto Alegre, Rio Grande do Sul, Brazil, testing possible associations with demographic, workrelated, and stress-related variables. The target population consisted of 217 teachers, of whom 190 participated (87.5\%). The Maslach Burnout Inventory (MBI) was used to measure burnout, together with a questionnaire to record the other variables. The results showed that teachers have a low score in the three dimensions comprising burnout: emotional exhaustion, depersonalization, and decreased personal fulfillment at work. Demographic variables did not show any association with burnout, while occupational variables, workload, and number of students were associated with emotional exhaustion. Bad conduct by students, family expectations, and limited participation in institutional decisions were the stress factors associated with burnout.
\end{abstract}

Professional Burnout; Stress; Occupational Health
Mary Sandra Carlotto 1

Lílian dos Santos Palazzo ${ }^{1}$

\section{Introdução}

A estrutura social vigente, que privilegia as leis do mercado, também se vê refletida no âmbito educacional, sendo a escola avaliada a partir de parâmetros de produtividade e eficiência empresarial 1. Nesse contexto, os professores, como trabalhadores, passaram a preocupar-se não só com suas funções docentes, mas também com questões baseadas no paradigma da civilização industrial, isto é, sua estabilidade e salário.

No atual modelo, muitas são as atribuições impostas ao professor, aparte de seu interesse e, muitas vezes, de sua carga horária. Além das classes, deve fazer trabalhos administrativos, planejar, reciclar-se, investigar, orientar alunos e atender aos pais. Também deve organizar atividades extra-escolares, participar de reuniões de coordenação, seminários, conselhos de classe, efetuar processos de recuperação, preenchimento de relatórios periódicos e individuais e, muitas vezes, cuidar do patrimônio material, recreios e locais de refeições. Entretanto, é excluído das decisões institucionais, das reestruturações curriculares, do repensar da escola, sendo concebido como mero executor de propostas e idéias elaboradas por outros. Com isso, estabelece-se uma tendência ao trabalho individualista, que não permite ao professor confrontar e transformar os aspectos estruturais de seu trabalho. Essa intensificação do fa- 
zer docente lhe ocasiona conflitos, pois, ao ter que arcar com essa sobrecarga, vê reduzido seu tempo disponível para estudos individuais ou em grupo, participação de cursos ou outros recursos que possam contribuir para a sua qualificação, favorecer seu desenvolvimento e sua realização profissional 2,3,4.

Frente a essas questões, fica evidente que, tanto na natureza do trabalho do professor como no contexto em que exerce suas funções, existem diversos estressores que, se persistentes, podem levar à síndrome de burnout. Essa síndrome é considerada por Harrison 5 como um tipo de estresse de caráter duradouro vinculado às situações de trabalho, sendo resultante da constante e repetitiva pressão emocional associada ao intenso envolvimento com pessoas por longos períodos de tempo.

A definição mais aceita sobre a síndrome de burnout fundamenta-se na perspectiva socialpsicológica de Maslach \& Jackson 6 . Essa considera burnout como uma reação à tensão emocional crônica por lidar excessivamente com pessoas. É um construto formado por três dimensões relacionadas, mas independentes: (a) exaustão emocional: caracterizada por falta de energia e entusiasmo, por sensação de esgotamento de recursos ao qual pode somar-se o sentimento de frustração e tensão nos trabalhadores, por perceberem que já não têm condições de despender mais energia para o atendimento de seu cliente ou demais pessoas, como faziam antes; (b) despersonalização: caracterizada pelo desenvolvimento de uma insensibilidade emocional, que faz com que o profissional trate os clientes, colegas e a organização de maneira desumanizada; (c) diminuição da realização pessoal no trabalho: caracterizada por uma tendência do trabalhador a autoavaliar-se de forma negativa, tornando-se infeliz e insatisfeito com seu desenvolvimento profissional, com conseqüente declínio no seu sentimento de competência e êxito, bem como de sua capacidade de interagir com os demais.

Burnout em professores afeta o ambiente educacional e interfere na obtenção dos objetivos pedagógicos, levando esses profissionais a um processo de alienação, desumanização e apatia, ocasionando problemas de saúde, absenteísmo e intenção de abandonar a profissão 7,8. Ainda que esse assunto tenha sido foco de investigação em vários países, no Brasil, encontramos poucos estudos que abordam a síndrome de burnout em professores 9,10,11, principalmente quanto a sua associação com fatores de estresse.

Assim, considerando que burnout é um fenômeno psicossocial relacionado diretamente à situação laboral; que o homem busca consti- tuir-se como sujeito através de seu trabalho e que o mesmo não se realiza de forma individual, mas sim se materializa num espaço social; e que a atividade produtiva é um elemento constitutivo da saúde mental individual e coletiva, este estudo teve como objetivo avaliar a síndrome de burnout em professores de escolas particulares de uma cidade da região metropolitana de Porto Alegre, Rio Grande do Sul, Brasil, verificando possíveis associações com variáveis demográficas, laborais e fatores de estresse percebidos no trabalho. Baseou-se nas seguintes hipóteses: H1 - variáveis demográficas se associam à síndrome de burnout; H2 variáveis laborais se associam à síndrome de burnout; $\mathrm{H} 3$ - fatores de estresse se associam à síndrome de burnout.

\section{Método}

No local onde foi realizada a investigação, funcionam 35 escolas municipais, 19 estaduais e seis particulares que possuem ensino Médio e Fundamental. Assim, a população do estudo foi de 217 indivíduos, que perfazem a totalidade dos professores, em exercício, de todas as seis escolas particulares de uma cidade da região metropolitana de Porto Alegre. Essas são instituições de ensino de médio porte, que possuem ensino Médio e Fundamental (obrigatórios). As escolas se equivalem, pois o número de professores em cada uma varia entre 40 a 58 , e o de alunos, entre 650 a 800, e todas são vinculadas a instituições religiosas. Foram excluídos os que exerciam somente atividades administrativas. O número total de participantes correspondeu a 190 sujeitos, isto é, $87,5 \%$ da população.

Para o levantamento dos dados, utilizou-se um instrumento auto-aplicado composto de quatro blocos de questões: (1) dados demográficos: sexo, idade, estado civil e filhos; (2) profissionais: titulação, nível de ensino, turno de trabalho, tempo de experiência profissional, tempo de experiência na escola, carga horária semanal, número de alunos que atende diariamente e se trabalha exclusivamente na instituição; (3) variáveis psicossociais - fatores de estresse percebidos pelos professores: mau comportamento de alunos, sobrecarga de atividades, elevado número de alunos por classe, necessidade de atualização profissional, execução de atividades burocráticas, multiplicidade de papéis a desempenhar, expectativas dos familiares, falta de recursos materiais para o trabalho, elevado número de disciplinas, relacionamento pais-professores, falta de apoio de 
coordenação e colegas, e pouca participação em decisões institucionais; (4) Maslach Burnout Inventory - MBI 12: para avaliar a síndrome de burnout.

Esse último avalia como o sujeito vivencia seu trabalho, de acordo com três dimensões estabelecidas pelo Modelo de Maslach: (a) exaustão emocional - nove itens (sinto-me emocionalmente decepcionado com meu trabalho; quando termino minha jornada de trabalho, sinto-me esgotado; quando me levanto pela manhã e enfrento outra jornada de trabalho, sinto-me fatigado; sinto que trabalhar todo o dia com pessoas me cansa; sinto que meu trabalho está me desgastando; sinto-me frustrado com meu trabalho; sinto que estou trabalhando demais; sinto que trabalhar em contato direto com as pessoas me estressa; sinto como se estivesse no limite de minhas possibilidades); (b) despersonalização - cinco itens (sinto que estou tratando algumas pessoas de meu trabalho como se fossem objetos impessoais; sinto que me tornei mais duro com as pessoas desde que comecei esse trabalho; preocupo-me se esse trabalho está me enrijecendo emocionalmente; sinto que realmente não me importa o que ocorra com as pessoas as quais tenho que atender profissionalmente; parece-me que os receptores de meu trabalho culpam-me por alguns de seus problemas); e (c) diminuição da realização pessoal no trabalho - oito itens (sinto que posso entender facilmente as pessoas que tenho que atender; sinto que trato com muita eficiência os problemas das pessoas as quais tenho que atender; sinto que estou exercendo influência positiva na vida das pessoas que tenho que atender; sinto-me vigoroso em meu trabalho; sinto que posso criar um clima agradável em meu trabalho; sinto-me estimulado depois de haver trabalhado diretamente com quem tenho que atender; creio que consigo coisas valiosas nesse trabalho; no meu trabalho, eu manejo os problemas emocionais com muita calma). Totaliza, portanto, 22 itens que indicam a freqüência das respostas, numa escala de pontuação que varia de 1 a 7 . Neste estudo, adotamos o sistema de pontuação de 1 a 5 , sendo 1 para "nunca", 2 para "algumas vezes ao ano", 3 para "algumas vezes ao mês", 4 para indicar "algumas vezes na semana" e 5 para "diariamente" 13,14. A variável burnout é estimada através do cálculo da média das pontuações obtidas em cada dimensão, o que dará o índice alcançado em cada uma delas. O MBI possui validez fatorial e consistência interna de suas escalas satisfatórias 15 . A validez convergente e a divergente são igualmente aceitáveis e não apresentam problemas especiais 9 .
A aplicação ocorreu nos meses de setembro e outubro de 2000. Foi realizada em um único encontro por escola, ou seja, no dia de reunião bimestral de professores, a fim de evitar possíveis perdas de respondentes. Foi colocado para o grupo tratar-se de uma investigação acadêmica de iniciativa da autora principal, tendo como objetivo avaliar o estresse ocupacional do professor. Foi esclarecido aos professores tratar-se de uma pesquisa sem quaisquer efeitos avaliativos individuais e/ou institucionais e que as respostas seriam anônimas e confidenciais. Após o preenchimento do instrumento, esse era depositado pelo professor em uma urna, garantindo o anonimato e a confidencialidade dos dados obtidos. Foi realizada análise descritiva, a fim de apresentar os índices médios alcançados em cada uma das dimensões da variável dependente burnout e as freqüências das variáveis independentes demográficas, profissionais e fatores de estresse percebidos. Por último, realizamos análises bivariadas com a variável dependente burnout e com as demais variáveis independentes, por meio de correlação de Pearson, prova t de Student e ANOVA.

\section{Resultados}

Os professores, em sua maioria, são do sexo feminino $(78,9 \%)$, casados $(64,9 \%)$ e possuem filhos $(58,4 \%)$. A faixa etária de maior concentração é de 31 a 40 anos (39,7\%), sendo que a média de idade é de 36,8 anos. Distribuem-se de forma equilibrada nos dois níveis de ensino, Fundamental $(37,1 \%)$ e Médio $(26,9 \%)$, sendo que $36 \%$ desenvolvem suas atividades em ambos os níveis. A maioria trabalha mais de vinte horas semanais (51\%) e contata diariamente com até cem alunos $(66,9 \%)$. A quase totalidade dos professores desenvolve atividades docentes em horário extraclasse $(96,2 \%)$, e muitos também exercem outras atividades profissionais (59\%). Os professores possuem, em média, 13 anos de experiência profissional (DP = $8,88)$, sendo dez anos sua experiência na instituição atual $(\mathrm{DP}=8,05)$.

Quanto aos índices de burnout, verificou-se que a exaustão emocional foi a dimensão que atingiu maior índice médio $(2,30)$, seguida pela dimensão da diminuição da realização pessoal no trabalho $(1,63)$, sendo que a de menor índice foi a despersonalização $(1,49)$ (Figura 1).

Quando foi analisada a relação entre as dimensões de burnout e as variáveis demográficas, não foi encontrada associação significativa $(\mathrm{p}<0,05)$. O mesmo ocorreu entre as dimen- 
Figura 1

Índices médios das subescalas de Burnout.

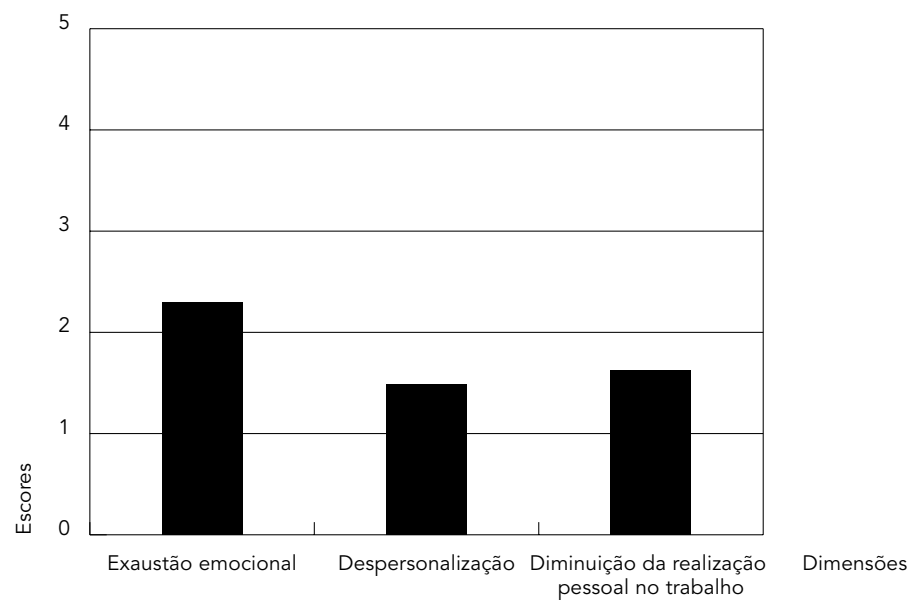

pessoal no trabalho sões de burnout e características profissionais dos professores como titulação, nível de ensino, turno e quantidade de turnos em que exercem suas atividades. Somente foi encontrada associação entre a exaustão emocional e o número de alunos e a carga horária docente, indicando que quanto maior o número de alunos $(\mathrm{r}=0,195)$ e o número de horas trabalhadas $(\mathrm{r}=$ 0,157 ) por um professor, maior tende a ser o seu escore dessa dimensão.

Com relação aos fatores de estresse percebidos pelo professor em relação ao trabalho, verificou-se que apenas o fator expectativas familiares em relação ao trabalho do professor apresentou associação com a dimensão exaustão emocional. Assim, perceber expectativas familiares como um fator de estresse aumenta o sentimento de exaustão emocional no docente (Tabela 1 ).

Já a dimensão de despersonalização evidenciou associação com expectativas familiares, mau comportamento dos alunos e falta de participação nas decisões institucionais. A percepção de que esses são fatores de estresse ocasiona um aumento do distanciamento afetivo (Tabela 2).

O fator mau comportamento dos alunos mostrou associar-se com a dimensão diminuição da realização pessoal no trabalho. Assim, perceber o comportamento inadequado de alunos como fator de estresse faz com que os professores apresentem maior sentimento de falta de realização profissional (Tabela 3).

\section{Discussão}

Segundo o modelo teórico de Maslach 16, a síndrome de burnout é um processo em que a exaustão emocional é a dimensão precursora da síndrome, sendo seguida por despersonalização e, por fim, pelo sentimento de diminuição da realização pessoal no trabalho. Assim, os resultados obtidos no presente estudo apontam para a possibilidade desse processo encontrar-se em curso na população estudada. Entretanto, pode estar sendo contido pelo sentimento de realização profissional no trabalho, tendo em vista que essa foi a dimensão de maior pontuação média $(3,51)$.

Os altos escores obtidos na dimensão da diminuição da realização pessoal no trabalho podem ser analisados de acordo com aspectos culturais da organização. Segundo Garay 17, a cultura organizacional é o conjunto de compreensões, interpretações ou perspectivas compartilhadas pelos indivíduos. Funcionam como um mecanismo de controle que busca restaurar as perdas psicológicas, repondo um quadro de valores, crenças e pressupostos orientadores de um comportamento coletivo conveniente aos objetivos organizacionais. As instituições particulares de caráter religioso, como as que foram estudadas, possuem uma cultura caritativa e assistencial. Percebem o trabalho docente também como uma "prática de bem ao próximo", que obtém, como prêmio, a "experiência de gratificação pessoal” 10, perpetuando alguns resquícios dos valores entranhados na construção sócio-histórica da profissão docente, ou seja, a de profissão vocacional, que exige abnegação e doação. Dessa forma, induz o profissional à repressão dos questionamentos sobre até que ponto o trabalho tem sido fator de realização e satisfação. Essa situação pode estar relacionada ao que Spink 18 denomina de ideologia gerencial, que, através de processos de doutrinação, estimula os funcionários a se censurarem e a evitar os assuntos tabus. Nesse sentido, Woods 19 alerta que professores com fortes sentimentos vocacionais são mais vulneráveis ao burnout, pois, ao não verem sua atividade como um trabalho, mas sim como uma vocação, tendem a envolver-se de forma excessiva com o mesmo, tendo como resultado a sobrecarga laboral.

É importante destacar que outras situações também podem estar influenciando esse resultado. Uma delas diz respeito às características demográficas e profissionais da população. Os professores, embora jovens, possuem experiência profissional e atuam na escola há bastante tempo. Professores com mais experiência pro- 
Relação entre a dimensão de exaustão emocional e fatores de estresse percebidos no trabalho. Professores de escolas privadas, Sul do Brasil, 2000.

\begin{tabular}{|c|c|c|c|c|c|c|c|}
\hline \multirow[t]{2}{*}{ Fatores de estresse } & \multicolumn{3}{|c|}{ Fator presente } & \multicolumn{3}{|c|}{ Fator ausente } & \multirow[t]{2}{*}{$p$} \\
\hline & $\mathrm{n}$ & Média & $\begin{array}{l}\text { Desvio } \\
\text { padrão }\end{array}$ & $\mathrm{n}$ & Média & $\begin{array}{l}\text { Desvio } \\
\text { padrão }\end{array}$ & \\
\hline Elevado número de alunos por classe & 89 & 2,30 & 0,63 & 101 & 2,30 & 0,62 & 0,964 \\
\hline Elevado número de disciplinas & 23 & 2,24 & 0,61 & 167 & 2,31 & 0,63 & 0,596 \\
\hline Execução de atividades burocráticas & 64 & 2,29 & 0,60 & 126 & 2,31 & 0,64 & 0,853 \\
\hline Expectativas familiares & 44 & 2,47 & 0,57 & 146 & 2,25 & 0,64 & $0,039 *$ \\
\hline Mau comportamento de alunos & 106 & 2,36 & 0,62 & 84 & 2,23 & 0,63 & 0,186 \\
\hline Falta de recursos materiais para o trabalho & 28 & 2,30 & 0,63 & 162 & 2,30 & 0,63 & 0,998 \\
\hline Multiplicidade de papéis a desempenhar & 63 & 2,31 & 0,58 & 127 & 2,30 & 0,65 & 0,870 \\
\hline Relacionamento pais-professores & 21 & 2,52 & 0,47 & 169 & 2,27 & 0,64 & 0,085 \\
\hline Pouca participação em decisões institucionais & 18 & 2,25 & 0,47 & 172 & 2,31 & 0,64 & 0,730 \\
\hline Sobrecarga de atividades & 103 & 2,38 & 0,59 & 87 & 2,21 & 0,65 & 0,077 \\
\hline Falta de apoio de coordenação e colegas & 20 & 2,19 & 0,65 & 170 & 2,32 & 0,62 & 0,398 \\
\hline Necessidade de atualização profissional & 77 & 2,24 & 0,52 & 113 & 2,34 & 0,69 & 0,271 \\
\hline
\end{tabular}

${ }^{*} p<0,05$

Tabela 2

Relação entre a dimensão de despersonalização e fatores de estresse percebidos no trabalho.

Professores de escolas privadas, Sul do Brasil, 2000.

\begin{tabular}{|c|c|c|c|c|c|c|c|}
\hline \multirow[t]{2}{*}{ Fatores de estresse } & \multicolumn{3}{|c|}{ Fator presente } & \multicolumn{3}{|c|}{ Fator ausente } & \multirow[t]{2}{*}{$\mathbf{p}$} \\
\hline & $\mathrm{n}$ & Média & $\begin{array}{l}\text { Desvio } \\
\text { padrão }\end{array}$ & $\mathrm{n}$ & Média & $\begin{array}{l}\text { Desvio } \\
\text { padrão }\end{array}$ & \\
\hline Elevado número de alunos por classe & 89 & 1,51 & 0,50 & 101 & 1,47 & 0,38 & 0,522 \\
\hline Elevado número de disciplinas & 23 & 1,38 & 0,47 & 167 & 1,51 & 0,44 & 0,220 \\
\hline Execução de atividades burocráticas & 64 & 1,50 & 0,43 & 126 & 1,48 & 0,45 & 0,779 \\
\hline Expectativas familiares & 44 & 1,61 & 0,49 & 146 & 1,46 & 0,42 & $0,043^{*}$ \\
\hline Mau comportamento de alunos & 106 & 1,55 & 0,47 & 84 & 1,42 & 0,39 & $0,042^{*}$ \\
\hline Falta de recursos materiais para o trabalho & 28 & 1,49 & 0,50 & 162 & 1,49 & 0,43 & 0,969 \\
\hline Multiplicidade de papéis a desempenhar & 63 & 1,46 & 0,41 & 127 & 1,51 & 0,45 & 0,463 \\
\hline Relacionamento pais-professores & 21 & 1,57 & 0,45 & 169 & 1,48 & 0,44 & 0,387 \\
\hline Pouca participação em decisões institucionais & 18 & 1,69 & 0,47 & 172 & 1,47 & 0,43 & $0,047 *$ \\
\hline Sobrecarga de atividades & 103 & 1,48 & 0,44 & 87 & 1,50 & 0,44 & 0,735 \\
\hline Falta de apoio de coordenação e colegas & 20 & 1,63 & 0,39 & 170 & 1,47 & 0,44 & 0,134 \\
\hline
\end{tabular}

* $p<0,05$

fissional apresentam menores níveis de burnout 20 . Os professores não evidenciam a percepção dos fatores de estresse que envolvem questões institucionais e relacionais, como participação em políticas e falta de suporte de coordenação e colegas. Trabalhadores que apresentam adequado suporte gerencial, participação nas decisões de grupo e nas metas organiza- cionais manifestam menores escores de burnout, de acordo com estudo realizado por Vallen 21.

Torna-se importante analisar o resultado quanto à dimensão despersonalização, pois essa é elemento essencial da síndrome de burnout, enquanto exaustão emocional e diminuição da realização pessoal no trabalho podem estar associadas a outros tipos de síndromes 22 . 
Tabela 3

Relação entre a dimensão da diminuição da realização pessoal no trabalho e fatores de estresse percebidos no trabalho.

Professores de escolas privadas, Sul do Brasil, 2000.

\begin{tabular}{|c|c|c|c|c|c|c|c|}
\hline \multirow[t]{2}{*}{ Fatores de estresse } & \multicolumn{3}{|c|}{ Fator presente } & \multicolumn{3}{|c|}{ Fator ausente } & \multirow[t]{2}{*}{$\mathrm{p}$} \\
\hline & $\mathrm{n}$ & Média & $\begin{array}{l}\text { Desvio } \\
\text { padrão }\end{array}$ & $\mathrm{n}$ & Média & $\begin{array}{l}\text { Desvio } \\
\text { padrão }\end{array}$ & \\
\hline Elevado número de alunos por classe & 89 & 1,63 & 0,51 & 101 & 1,64 & 0,48 & 0,807 \\
\hline Elevado número de disciplinas & 23 & 1,63 & 0,49 & 167 & 1,64 & 0,50 & 0,917 \\
\hline Execução de atividades burocráticas & 64 & 1,62 & 0,42 & 126 & 1,65 & 0,53 & 0,694 \\
\hline Expectativas familiares & 44 & 1,68 & 0,48 & 146 & 1,62 & 0,50 & 0,530 \\
\hline Mau comportamento de alunos & 106 & 1,70 & 0,52 & 84 & 1,55 & 0,45 & $0,043^{*}$ \\
\hline Falta de recursos materiais para o trabalho & 28 & 1,72 & 0,52 & 162 & 1,62 & 0,49 & 0,312 \\
\hline Multiplicidade de papéis a desempenhar & 63 & 1,64 & 0,49 & 127 & 1,63 & 0,50 & 0,940 \\
\hline Relacionamento pais-professores & 21 & 1,71 & 0,39 & 169 & 1,63 & 0,50 & 0,472 \\
\hline Pouca participação em decisões institucionais & 18 & 1,60 & 0,33 & 172 & 1,64 & 0,51 & 0,781 \\
\hline Sobrecarga de atividades & 103 & 1,65 & 0,47 & 87 & 1,62 & 0,52 & 0,680 \\
\hline Falta de apoio de coordenação e colegas & 20 & 1,71 & 0,49 & 170 & 1,63 & 0,49 & 0,467 \\
\hline Necessidade de atualização profissional & 77 & 1,67 & 0,50 & 113 & 1,61 & 0,49 & 0,373 \\
\hline
\end{tabular}

* $p<0,05$.

Chama a atenção o fato de que grande parte dos professores nega sentimentos de distanciamento de seus alunos, uma vez que o mau comportamento do aluno foi o elemento mais assinalado por eles como fator de estresse percebido no trabalho. Segundo Farber 13, algumas pessoas podem não ter condições de reconhecer, verdadeiramente, o que está ocorrendo com elas próprias, o que dificultaria a identificação de questões relacionadas a essa dimensão. Além disso, esse resultado pode estar associado ao conteúdo das perguntas formuladas, pois, segundo Benevides-Pereira 23, algumas questões do inventário podem causar um certo impacto, uma vez que entram em desacordo com a postura esperada de um bom profissional. Assim, pode ter sido difícil para o professor revelar certas atitudes suas no trabalho, tais como não tratar seus alunos com afetividade, uma vez que essa é uma importante expectativa de pais, administração escolar e sociedade em geral, fazendo parte do perfil idealizado do professor. Deve-se considerar, também, que socialmente é aceitável sentir-se exausto em função do trabalho e, em muitos casos, isso faz com que o profissional seja mais valorizado, sendo inclusive reforçado pelo corpo diretivo, que passa a ver esses trabalhadores como dedicados e comprometidos com as metas e objetivos institucionais, estratégia essa bastante utilizada pelas organizações na busca de mais produtividade.

Na comparação entre os índices obtidos nas três dimensões de burnout e as variáveis de- mográficas, sexo, idade, estado civil e ter filhos, a ausência de diferenças estatisticamente significativas confirma estudos já realizados com relação às variáveis sexo e estado civil 6,20,24. Já no que diz respeito às variáveis idade e ter filhos, os resultados obtidos vão de encontro aos demonstrados em outras investigações, que referem que trabalhadores mais jovens apresentam maiores níveis de burnout, e indivíduos com filhos, os menores níveis 11,25,26.

De um modo geral, esses resultados confirmam os achados na literatura, os quais não identificam as variáveis demográficas como as que possuem maior poder preditivo e de associação com burnout 27,28,29,30, corroborando a concepção mais atual de que “(...) Burnout não é um problema do indivíduo, mas do ambiente social no qual o indivíduo trabalha" 27 (p. 18). Dessa forma, não confirmamos a primeira hipótese do estudo (H1) de que existiria associação entre a síndrome de burnout e variáveis demográficas.

Na comparação entre burnout, variáveis profissionais e psicossociais como o estresse percebido no trabalho, verificamos que o número de alunos atendidos diariamente associou-se positiva e significativamente com a exaustão emocional, resultado também encontrado por outros autores 10,31. Cordes \& Dougherty 32 referem que a uma elevação no número de clientes corresponde um aumento de demandas, tornando o trabalhador mais vulnerável ao burnout. Esse resultado confirma o que tem sido entendido como uma das principais 
variáveis associadas à síndrome, ou seja, a relação profissional-cliente. A carga horária também indica ser um elemento associado à exaustão emocional. A crescente expansão do ensino privado tem gerado um aumento do número de alunos atendendo ao paradigma da empresa-escola (mais clientes, maior lucratividade) bem como às expectativas do cliente financeiro: os pais dos alunos. Assim, para atender mais alunos e mais atividades, o professor tem sido impelido a aumentar sua carga horária laboral, o que pode resultar no aumento do sentimento de esgotamento emocional. Esse resultado confirma os encontrados na literatura, principalmente em estudos realizados com trabalhadores americanos de uma empresa pública, com trabalhadores sociais canadenses, com professores universitários brasileiros e com médicos e enfermeiros brasileiros 23,33,34,35.

Considerando que burnout é a etapa final das progressivas tentativas de lidar com os fatores de estresse no trabalho 26 , torna-se importante discutirmos a associação dos fatores de estresse mais comuns na atividade docente com as dimensões da síndrome.

Assim, os fatores de estresse associados às dimensões de burnout foram: expectativas familiares com relação ao trabalho docente, mau comportamento de alunos e falta de participação nas decisões institucionais. Os sentimentos de esgotamento emocional e de distanciamento relacionam-se com a percepção docente de que as expectativas dos familiares atuam como fator de estresse. Esse resultado corrobora os achados de outra pesquisa com professores canadenses 24 , e podemos entender esse resultado a partir da análise que Esteve 2 faz sobre o papel do professor frente às modificações dos agentes tradicionais de socialização, neste caso, a família. Para o autor ${ }^{2}$, a modificação da dinâmica familiar e o aumento do trabalho feminino impulsionaram os pais a que delegassem parte de sua função educativa à escola e ao professor. Farber 13 complementa, referindo que a relação do professor com familiares se mostra, muitas vezes, problemática e estressante, seja ela pela falta de envolvimento desses últimos no processo educacional, acreditando que a escola e o professor são os únicos responsáveis pela educação dos filhos, ou pelo excesso, acreditando ser o professor incompetente e inexperiente e, muitas vezes, causador dos problemas apresentados pelo aluno. Cherniss 36 diz que muitos pais acreditam que os professores estão mais preocupados com seu contracheque e com suas férias do que com a educação. Nenhuma categoria tem sido tão severamente avaliada e cobrada pela população em geral, nas últimas duas décadas, como a dos professores. São extremamente cobrados em seus fracassos e raramente reconhecidos por seu sucesso ${ }^{13}$. Frente ao exposto, não surpreende o fato de que os professores estudados tenham associado esse fator à exaustão emocional e ao mecanismo defensivo de despersonalização frente à sua clientela, neste caso, os pais.

Perceber o mau comportamento dos alunos e a falta de participação nas decisões institucionais como fatores de estresse, também, apresentou relação com despersonalização, sendo semelhante ao encontrado em outros estudos com professores suíços e americanos 37,38. A relação professor-aluno se apresenta como o componente fundamental da atividade docente e é nessa relação que emerge a essência da função. Assim, pode ser fonte de prazer quando essa relação se estabelece de forma adequada e satisfatória, ou pode funcionar como elemento de tensão e estresse quando ocorre o contrário. Os alunos, segundo Nacarato et al. 3 , trazem para a sala de aula suas vivências e tentam exercer seu direito de livre expressão, não se importando com o conteúdo e a forma de fazê-lo. A falta de limites dos alunos ocasiona situações de falta de respeito aos direitos e diferenças com relação aos outros personagens do ambiente escolar, e o professor é um deles. Muitas vezes, parece haver uma inversão completa do poder, em que os alunos passam a controlar as mais diversas situações em sala de aula. Tudo isso sem mecanismos que possam arbitrar, com justiça e imparcialidade, as relações de convívio social, dificultando o trabalho pedagógico do professor e lhe exigindo um grande dispêndio de energia. O mau comportamento dificulta a tarefa docente, na medida em que os professores não conseguem responder positivamente aos objetivos de seu trabalho, que são o de transmitir saberes, atitudes, valores e cultura 39. A falta de reciprocidade na relação com alunos tem sido apontada como um importante elemento, pois a relação profissional-cliente é a variável que mais se associa ao burnout 40,41,42. Esse resultado é reforçado pela ocorrência de associação desse fator de estresse também com a dimensão de diminuição da realização pessoal no trabalho.

A escola, segundo Carvalho ${ }^{9}$, vem assumindo cada vez mais características e modelos de gestão empresarial, não podendo ser considerada, hoje, apenas uma pequena empresa, devido à sua complexidade, organização, número de funcionários e clientes atendidos. Assim, os resultados obtidos parecem dar sustentação ao modelo sociológico de burnout proposto por Woods 19, que entende o estresse e a síndrome 
de burnout em professores a partir de fatores localizados em níveis micro, meso e macrossocias. Para o autor, os fatores microssociais seriam aqueles situados dentro da atividade profissional (comprometimento, papéis desenvolvidos, relacionamentos profissionais), neste estudo, representados pelos fatores de interação, como a relação estabelecida com os alunos e as provenientes da relação com os pais na forma de expectativas com relação ao seu trabalho. Os fatores intermediários (políticas institucionais, aspectos éticos da escola, aspectos culturais do professor e dos alunos), no estudo, representados pela participação nas políticas institucionais, e os macrossocias seriam todas as forças derivadas das tendências globais e políticas governamentais, podendo ser entendidos como o novo paradigma estabelecido a partir da concepção de escola como empresa enquanto prestadora de serviços.

Assim, considerando os resultados obtidos, em que as dimensões dessa síndrome apresentaram associação com determinadas variáveis profissionais e determinados fatores de estresse percebidos no trabalho, foram confirmadas parcialmente a segunda (H2) e terceira (H3) hipóteses do estudo. Ainda, os dados levantados sugerem como possíveis fatores de risco de burnout: índice de exaustão emocional com tendência a médio, elevado número de alunos e carga horária e percepção; como fatores de estresse no trabalho: a pouca participação nas decisões, o mau comportamento de alunos e as expectativas que os familiares têm sobre o trabalho docente.

Finalizando, é importante ressaltar que, ainda que o estudo tenha obtido dados importantes sobre o problema, deve-se considerar as limitações do mesmo principalmente em relação à validez externa, uma vez que os professores estudados pertencem a escolas particulares, exercendo suas atividades em um contexto diferente daquele em que se inserem as escolas públicas. No entanto, boa parcela das pesquisas encontradas na literatura internacional não especifica se as escolas são privadas ou não. Acreditamos que isso ocorra devido a que, em outros países, não há essa dicotomia escola pública/privada de forma tão acentuada como no modelo educacional vigente em países em desenvolvimento, como o Brasil. Entretanto, considerando que as escolas privadas nacionais possuem um padrão organizacional e de condições de trabalho semelhantes ao de mui- tas sociedades, os resultados deste estudo tornam-se passíveis de comparações.

Além disso, os dados obtidos configuram um importante objeto de reflexão aos que trabalham em saúde coletiva, já que essa entende que o conhecimento não se dá pelo simples contato com a realidade e sim pela compreensão de suas regras e pelo comprometimento com as forças capazes de transformá-la 43 . O que ocorre com professores não pode ser desvinculado dos vários aspectos sociais ligados ao trabalho em geral e que têm contribuído para elevar a carga de morbidade em trabalhadores. Dentre esses, destaca-se a crescente intensidade das relações humanas no âmbito laboral, a pressão procedente das novas características econômicas próprias da globalização, a crescente competitividade, assim como a evidência de um incremento da violência psicológica nos ambientes de trabalho. Esses têm assumido papel significativo como fatores de risco psicossociais na saúde laboral no século XXI e têm levado diversos organismos internacionais (Organização Internacional do Trabalho OIT, Organização Mundial da Saúde - OMS) a chamar a atenção para o problema e a impulsionar grupos de trabalho e estudos que permitam um conhecimento mais detalhado da situação e das estratégias de prevenção e intervenção 44 .

Assim, pensa-se que a prevenção e a erradicação do burnout em professores não são uma tarefa solitária desses, mas devem contemplar ações conjuntas entre professores, alunos, instituições de ensino e sociedade. Sugerem-se atividades que estabeleçam um contexto mais favorável ao exercício da profissão docente através de programas voltados às equipes diretivas e pedagógicas das escolas, a fim de que possam propiciar um espaço institucional de discussão e reflexão entre equipes e professores. Também, atividades direcionadas aos docentes, alertando-os sobre os possíveis fatores de estresse relacionados ao trabalho e a possibilidade de desenvolvimento desse tipo de estresse ocupacional de caráter crônico (burnout).

As intervenções devem visar à busca de alternativas para possíveis modificações, não só na esfera microssocial do trabalho e das relações interpessoais, mas também na ampla gama de fatores macroorganizacionais que determinam aspectos constituintes da cultura organizacional e social na qual o professor exerce sua atividade profissional. 


\section{Resumo}

O estudo apresenta os resultados obtidos em uma investigação sobre a síndrome de burnout em professores de escolas particulares de uma cidade da região metropolitana de Porto Alegre, Rio Grande do Sul, Brasil. Trata-se de um estudo epidemiológico que buscou identificar o nível da síndrome de burnout, verificando possíveis associações com variáveis demográficas, laborais e fatores de estresse percebidos no trabalho. A população do estudo estava composta por 217 professores, dos quais, participaram 190 sujeitos (87,5\%). Como instrumento de pesquisa, utilizou-se o MBI para medir burnout, associado a um questionário para o levantamento das demais variáveis. Os resultados obtidos revelaram que professores apresentam nivel baixo nas três dimensões que compõem burnout: exaustão emocional, despersonalização e diminuição da realização pessoal no trabalho. Variáveis demográficas não apresentaram relação com as dimensões de burnout, sendo que, das variáveis profissionais, a carga horária e a quantidade de alunos atendidos foram as que mostraram associação com a dimensão de exaustão emocional. Mau comportamento dos alunos, expectativas familiares e pouca participação nas decisões institucionais foram os fatores de estresse que apresentaram associação com as dimensões de burnout.

Estafa Profissional; Estresse; Saúde Ocupacional

\section{Referências}

1. Frigotto G. Educação e formação humana: ajuste neoconservador e alternativa democrática. In: Gentili PAA, Silva TT, organizadores. Neoliberalismo, qualidade total e educação. Petrópolis: Editora Vozes; 1999. p. 31-92.

2. Esteve JM. O mal-estar docente: a sala de aula e a saúde dos professores. São Paulo: EDUSC; 1999.

3. Nacarato AM, Varani A, Carvalho V. O cotidiano do trabalho docente: palco, bastidores e trabalho invisível...abrindo as cortinas. In: Geraldi CMG, Fiorentina D, Pereira EMA, organizadores. Cartografias do trabalho docente. Campinas: Mercado de Letras; 2000. p. 45-79.

4. Schnetzler RP. Prefácio. In: Geraldi CMG, Fiorentina D, Pereira EMA, organizadores. Cartografias do trabalho docente. Campinas: Mercado de Letras; 2000. p. 7-9.

5. Harrison BJ. Are you to burn out? Fund Raising Manage 1999; 30:25-8.

6. Maslach C, Jackson SE. The measurement of experienced burnout. Journal of Occupational Behavior $1981 ; 2: 99-113$.

7. Guglielmi RS, Tatrow K. Occupational stress, burnout, and health in teachers: a methodological and theoretical analysis. Review of Educational Research 1998; 68:61-9.

\section{Colaboradores}

M. S. Carlotto realizou a pesquisa bibliográfica, coletou e revisou os dados da pesquisa, realizou as tabulações e análises, redigiu a versão preliminar do trabalho e participou da edição e revisão da versão final do artigo. L. S. Palazzo participou nas análises e na edição e revisão final do artigo.
8. Codeiro JAC, Gullén IG, Gala-León FJL, Lupiani MG, Benítez AG, Gomes AS. Prevalencia del síndrome de burnout en los maestros: resultados de una investigación preliminar. Psicología 2003; 7(1). http://132.248.25.54/articulo12.html (acessado em 25/Mar/2004).

9. Carvalho MMB. O professor: um profissional, sua saúde e a educação em saúde na escola [Tese de Doutorado]. São Paulo: Faculdade de Saúde Pública, Universidade de São Paulo; 1995.

10. Moura EPG. Saúde mental e trabalho: esgotamento profissional em professores da rede de ensino particular de Pelotas - RS [Dissertação de Mestrado]. Porto Alegre: Instituto de Psicologia, Pontifícia Universidade Católica do Rio Grande do Sul; 1997.

11. Codo W. Educação: carinho e trabalho. Petrópolis: Editora Vozes; 1999.

12. Maslach C. Maslach burnout inventory. 2nd Ed. Palo Alto: Consulting Psychologist Press; 1986.

13. Farber BA. Crisis in education: stress and burnout in the American teacher. San Francisco: JosseyBass Inc.; 1991.

14. Tamayo RM. Relação entre a síndrome de burnout e os valores organizacionais no pessoal de enfermagem de dois hospitais públicos [Dissertação 
de Mestrado]. Brasília: Instituto de Psicologia, Universidade de Brasília; 1997.

15. Carlotto MS, Câmara SG. Análise fatorial do Malasch Burnout Inventory (MBI) em uma amostra de professores de instituições particulares. Psicol Estud 2004; 9:499-505.

16. Maslach C. Burnout: the cost of caring. Englewood Cliffs: Prentice Hall; 1982.

17. Garay A. Cultura organizacional. In: Cattani AD, organizador. Trabalho e tecnologia. Dicionário crítico. Porto Alegre: Editora da UFRGS/Petrópolis: Editora Vozes; 2000. p. 48-50.

18. Spink PK. Discurso e ideologia gerencial: reflexões a partir da experiência brasileira. In: Motta FP, Caldas MP, organizadores. Cultura organizacional e cultura brasileira. São Paulo: Editora Atlas; 1997. p. 305-15.

19. Woods P. Intensification and stress in teaching. In: Vanderbergue R, Huberman MA, editors. Understanding and preventing teacher burnout: a source book of international practice and research. Cambridge: Cambridge University; 1999. p. 115-38.

20. Mohammed AA. The effect of some personality traits, sex, and experience on teacher burnout. Derasat Nafseyah 1995; 5:345-76.

21. Vallen G. Organizational climate and burnout. Cornell Hotel Restaur Adm Q 1993; 43:54-60.

22. Moreno BJ, Oliver C, Aragoneses A. El burnout: una forma específica de estrés laboral. In: BuelaCasal G, Caballo V, editores. Manual de psicología clínica aplicada. Madri: Siglo Veintiuno; 1991. p. 271-84.

23. Benevides-Pereira AMT. Burnout: o processo de adoecer pelo trabalho. In: Benevides-Pereira AMT, organizador. Burnout: quando o trabalho ameaça o bem-estar do trabalhador. São Paulo: Casa do Psicólogo; 2002. p. 21-91.

24. Lautert L. O desgaste profissional do enfermeiro [Tese de Doutorado]. Salamanca: Facultad de Psicología, Universidade Pontificia de Salamanca; 1995.

25. Cherniss C. Professional burnout in human service organizations. New York: Praeger; 1980.

26. Byrne B. Burnout: investigating the impact of background variables for elementary, intermediate, secondary, and university educators. Teaching \& Teacher Education 1991; 7:197-209.

27. Maslach C, Leiter MP. The truth about burnout: how organization cause, personal stress and what to do about it. San Francisco: Jossey-Bass; 1997.

28. Maslach C, Schaufeli, WB, Leiter MP. Job burnout. Annu Rev Psychol 2001; 52:397-422.
29. Silva GN, Carlotto MS. Síndrome de burnout: um estudo com professores da rede pública. Psicologia Escolar e Educacional 2003; 7:145-53.

30. Smith D, Goh WL. Prevalence and sources of burnout in Singapore secondary school physical education teachers. Journal of Teaching in Physical Education 2003; 22:203-18.

31. Russell DW, Altmaier E, van Velzen D. Job-related stress, social support, and burnout among classroom teachers. J Appl Psychol 1987; 72:269-73.

32. Cordes CL, Dougherty TW. A review and integration of research on job burnout. Acad Manage Rev 1993; 18:632-6.

33. Maslach C. "Burned-out". Hum Behav 1976; 5:1622.

34. Lee RT, Ashforth BE. A further examination of managerial burnout: toward an integrated model. Journal of Organizational Behavior 1993; 14:3-20.

35. Carlotto MS. Síndrome de burnout e satisfação no trabalho: um estudo com professores universitários. In: Benevides-Pereira AMT, organizador. Burnout: quando o trabalho ameaça o bem-estar do trabalhador. São Paulo: Casa do Psicólogo; 2002. p. 187-212.

36. Cherniss C. Beyond burnout. New York: Roulege; 1995.

37. Huberman M. Burnout in teaching careers. European Education 1993; 25:47-69.

38. Kyriacou C. Teacher stress and burnout: an international review. Educational Research 1987; 29: 146-52.

39. Arroyo MG. Ofício de mestres: imagens e autoimagens. Petrópolis: Editora Vozes; 2000.

40. Bakker AB, Kilmer CH, Siegrist J, Schaufeli WB. Effort-reward imbalance and burnout among nurses. J Adv Nurs 2000; 31:884-91.

41. Heus P, Diekstra RFW. Do you teachers burnout more easily? A comparison of teachers with other social professions on work stress and burnout symptoms. In: Vanderbergue R, Huberman MA, editors. Understanding and preventing teacher burnout: a source book of international practice and research. Cambridge: Cambridge University Press; 1999. p. 269-84.

42. Schaufeli WM, Maslach C, Marek T. Professional burnout: recent developments in theory and research. New York: Taylor \& Francis; 1993.

43. Paim JS. Saúde, política e reforma sanitária. Salvador: Instituto de Saúde Coletiva, Universidade Federal da Bahia; 2002.

44. Luna, M. Acoso psicológico en el trabajo (Mobbing). Madrid: Ediciones GPS; 2003.

Recebido em 28/Mar/2005

Versão final reapresentada em 16/Set/2005 Aprovado em 14/Out/2005 